the diagnosis of subacute thyroiditis. These findings and those in our previous report of normal erythrocyte zinc concentrations in pregnant women with hyperemesis gravidarum ${ }^{2}$ show that the measurement of erythrocyte zinc concentration may be useful in distinguishing transient hyperthyroid states from established hyperthyroidism and might therefore be a valuable addition to the current range of thyroid function tests. Measurement of erythrocyte zinc concentration is fairly simple and provides information that cannot be obtained by conventional thyroid function tests. It may alert the clinician to the correct diagnosis, particularly in patients with "silent" thyroiditis with associated thyrotoxicosis, and therefore avoid inappropriate treatment.

I Swaminathan R, Segall NH, Chapman C, Morgan DB. Red blood cell omposition in thyroid disease. Lancet 1976;ii: 1382-5.

Lao TTH, Chin RKH, Swaminathan R, Panesar NS, Cockram CS. Erythrocyte anc in differential diagnosis of hyperthyroidism in pregnancy: a preliminary report. Br Med 7 1987:294:1064-5.

(Accepted 21 September 1989)

\section{Renal replacement treatment in patients with spina bifida or spinal cord injury}

\author{
G S Muralikrishna, R S C Rodger, \\ A I Macdougall, J M Boulton-Jones, \\ M E M Allison, K F Kyle, B J R Junor, \\ J D Briggs
}

\section{Renal Unit, Stobhill General Hospital, Glasgow G21 3UW}

G S Muralikrishna, MRCP, registrar in medicine R S C Rodger, MRCP, consultant physician

A I Macdougall, FRCP consultant physician

Renal Unit, Royal Infirmary, Glasgow J M Boulton-Jones, FRCP, consultant physician M E M Allison, FRCP, senior lecturer in medicine

\section{Renal Unit, Western} Infirmary, Glasgow B J R Junor, FRCP, consultant physician

J D Briggs, FRCP, consultant physician

Department of Urology, Western Infirmary, Glasgow

K F Kyle, FRCs, consultant surgeon

Correspondence to: $\mathrm{Dr}$ Muralikrishna.

Br Med f 1989;299:1506

Number of new patients with chronic pyelonephritis secondary to neurogenic bladder who started dialysis in west of Scotland and United Kingdom per million population, 1982-8

\begin{tabular}{lll}
\hline & $\begin{array}{c}\text { West of } \\
\text { Scotland }\end{array}$ & $\begin{array}{c}\text { United } \\
\text { Kingdom }\end{array}$ \\
\hline 1982 & $0 \cdot 36$ & $0 \cdot 22$ \\
1983 & $0 \cdot 73$ & $0 \cdot 31$ \\
1984 & $0 \cdot 36$ & $0 \cdot 38$ \\
1985 & 0 & $0 \cdot 33$ \\
1986 & 1.09 & $0 \cdot 18$ \\
1987 & $2 \cdot 18$ & $0 \cdot 16$ \\
1988 & 0.73 & $\star$ \\
\hline
\end{tabular}

^Data not available.
Before 1980 few patients with spina bifida or traumatic paraplegia started dialysis in British renal units, probably because doctors had an unsubstantiated belief that their prognosis was poor ${ }^{1}$ and because of a lack of resources to fund renal replacement treatment. ${ }^{2}$ Since then, however, successful treatment of the elderly and diabetics with renal failure, two other groups of patients expected to have a poor prognosis, has been described. ${ }^{34}$ We report our experience of treating patients with renal failure due to spina bifida or spinal cord injury.

\section{Patients, methods, and results}

Fifteen of 883 adults starting dialysis in the west of Scotland from January 1982 to December 1988 had renal failure due to spina bifida or spinal cord injury. Data from the European Dialysis and Transplant Association's registry show the number of patients classified as having chronic pyelonephritis secondary to neurogenic bladder who started dialysis in the United Kingdom during this period (table). We studied the patients until the end of February 1989, a follow up of four to 78 months, and calculated cumulative survival by using actuarial analysis.

The patients ( 10 men, five women) were of mean age 27 (range 16-50) years at the time of first referral to a nephrologist. Twelve had spina bifida, two traumatic paraplegia, and one traumatic tetraplegia. Fourteen had been referred because of renal failure ( 12 with a serum creatinine concentration $>500 \mu \mathrm{mol} / \mathrm{l}$ ), and eight of these patients started dialysis within six months. In all cases renal failure was attributed to neurogenic bladder and recurrent urinary tract infections, but severe hypertension (seven patients), amyloidosis (two), shunt nephritis (one), and renal calculi (one) were identified as additional contributory factors.

Eleven patients were treated by haemodialysis ( $\mathrm{six}$ at home) for a mean of 20 (range 2-53) months and four patients by continuous ambulatory peritoneal dialysis for 27 (3 to 55) months. Thirteen patients were considered suitable for transplantation after further urological assessment. Three of these patients received transplants 31-58 months after starting dialysis; all grafts were functioning at follow up eight to 35 months after transplantation, serum creatinine concentrations being 61-124 $\mu \mathrm{mol} / \mathrm{l}$. Three patients died 12-35 months after starting dialysis; all had been treated by haemodialysis in hospital, and all deaths were related to infection. Cumulative survival rates were $93 \%$, 93\%, and $62 \%$ at one, two, and three years respectively.

\section{Comment}

This study shows that the outlook for patients with renal failure due to spina bifida or spinal cord injury is good in the short and medium term. Survival is better than that for diabetics with end stage renal disease in the region. Moreover, many of the patients can be treated by dialysis at home, and most are suitable candidates for renal transplantation. Previous reports of treating such patients are scarce, but our experience compares favourably with that in California, where survival rates at one and two years were $60 \%$ and $52 \%$ respectively.

The data from the registry of the European Dialysis and Transplant Association suggest that a higher proportion of patients with spina bifida or spinal cord injury receive renal replacement treatment in the west of Scotland than in the rest of the United Kingdom. This suggests that non-nephrologists in our region are more aware than those in the rest of the United Kingdom of the value of treating renal failure in patients with paraplegia. Regrettably, these patients were often referred in advanced renal failure, and this has been observed in other groups of patients expected to have a poor prognosis. Our results indicate that all patients with neurogenic bladder should be referred to a nephrologist as soon as their blood pressure or serum creatinine concentration is raised, as we have not found any such patient to be unsuitable for renal replacement treatment.

We thank Professor F P Brunner, chairman of the European Dialysis and Transplant Association's registration committee, for permission to use previously unpublished data; Ms Sheila Dykes for making these data available; Mr A Azmy, of the Royal Hospital for Sick Children, Glasgow, for his useful advice; and Ms Shona Smillie for secretarial help.

Whitfield HN, Hendry WF, eds. Textbook of genitourinary surgery. Edinburgh: Churchill Livingstone, 1985:782.

Wing AJ. Why don't the British treat more patients with kidney failure? Br.Med f 1983;287:1157-8.

Taube DH, Winder EA, Ogg CS, et al. Successful treatment of middle aged and elderly patients with endstage renal disease. Br Med f 1983;286:2018-20.

Cameron JS, Challah $\mathrm{S}$. Treatment of end stage renal failure due to diabetes in the United Kingdom, 1975-84. Lancet 1986;ii:962-6.

5 Mirahmadi MK, Vaziri ND, Ghobadi M, Nikakh B, Gordon S. Survival on maintenance dialysis in patients with chronic renal failure associated with paraplegia and quadriplegia. Paraplegia 1982;20:43-7.

(Accepted 27 September 1989) 